\title{
A formação do senso crítico no processo de ensino e aprendizagem como forma de
}

\section{superação do senso comum}

The formation of the critical sense in the teaching and learning process as a way to overcome the

common sense

La formación del sentido crítico en el proceso de enseñanza y aprendizaje como forma de superar el sentido común

Recebido: 31/05/2021 | Revisado: 07/06/2021 | Aceito: 07/06/2021 | Publicado: 22/06/2021

\author{
Ronualdo Marques \\ ORCID: https://orcid.org/0000-0001-6681-9914 \\ Universidade Federal do Paraná, Brasil \\ E-mail: ronualdo.marques@gmail.com \\ Talita Fraguas \\ ORCID: https://orcid.org/0000-0003-2048-456X \\ Universidade Tecnológica Federal do Paraná, Brasil \\ E-mail: tafraguas@hotmail.com
}

\begin{abstract}
Resumo
Este estudo apresenta reflexões sobre a formação do senso crítico no processo de ensino e aprendizagem, como forma de contribuir para a mudança de comportamento e atitudes em relação as questões e dilemas contemporâneos em superação ao senso comum. Metodologicamente, esta pesquisa se classifica como um estudo bibliográfico para a identificação e análise sobre a dicotomia entre (a)criticidade e criticidade, a transição do senso comum ao pensamento crítico e a elucidação do senso crítico no processo educativo. Certifica-se nesse estudo a importância da interação e inter-relação de aprendizagem e a função do professor, para a manifestação do pensamento crítico dos alunos, na qual os educadores têm papel estratégico e decisivo na inserção de temáticas que englobem as dimensões políticas, sociais, culturais, ambientais entre outras, qualificando os alunos para um posicionamento crítico em face aos dilemas das relações entre homem, sociedade e natureza, tendo como horizonte processos de humanização e de transformação social na formação para cidadania no seu significado mais abrangente.
\end{abstract}

Palavras-chave: Senso crítico; Ensino e aprendizagem; Senso comum.

\begin{abstract}
This study presents reflections on the formation of critical sense in the teaching and learning process, as a way to contribute to the change of behavior and attitudes towards contemporary issues and dilemmas in overcoming common sense. Methodologically, this research is classified as a bibliographical study for the identification and analysis on the dichotomy between (a) criticality and criticality, the transition from common sense to critical thinking and the elucidation of critical sense in the educational process. It is certified in this study the importance of interaction and interrelation of learning and the function of the teacher, for the manifestation of critical thinking of students, in which educators have strategic and decisive role in the insertion of themes that encompass the political, social, cultural, environmental dimensions among others, qualifying students for a critical positioning in the face of the dilemmas of relations between man, society and nature, having as horizon processes of humanization and social transformation in the formation for citizenship in its most comprehensive meaning.
\end{abstract}

Keywords: Critical sense; Teaching and learning; Common sense.

\section{Resumen}

Este estudio presenta reflexiones sobre la formación del sentido crítico en el proceso de enseñanza y aprendizaje, como una forma de contribuir al cambio de comportamiento y actitudes hacia los temas y dilemas contemporáneos en la superación del sentido común. Metodológicamente, esta investigación se clasifica como un estudio bibliográfico para la identificación y el análisis sobre la dicotomía entre (a) la criticidad y el sentido común, la transición del sentido común al pensamiento crítico y la elucidación del sentido crítico en el proceso educativo. Se certifica en este estudio la importancia de la interacción e interrelación de los aprendizajes y la función del docente, para la manifestación del pensamiento crítico de los estudiantes, en el que los educadores tienen un papel estratégico y decisivo en la inserción de temas que abarcan las dimensiones políticas, sociales, culturales, ambientales entre otras, capacitando a los estudiantes para un posicionamiento crítico frente a los dilemas de las relaciones entre el hombre, la sociedad y la naturaleza, teniendo como horizonte procesos de humanización y transformación social en la formación para la ciudadanía en su sentido más integral.

Palabras clave: Sentido critic; Enseñanza y aprendizaje; Sentido común. 


\section{Introdução}

Este estudo apresenta uma discussão sobre os elementos para a formação do senso crítico dentro da complexidade do pensamento e na perspectiva de ensino e aprendizagem no contexto da apropriação do conhecimento científico.

As reflexões sobre a formação do senso crítico são exploradas a partir do processo de contextualização no processo de ensino e aprendizagem é intrínseca a possibilidade de se estabelecer uma ligação com as temáticas políticas, sociais, econômicas, ambientais etc. O espaço escolar representa um ambiente extremamente significativo de socialização, sensibilização e formação da cidadania, promovendo a disseminação do conhecimento idealizando a formação de cidadãos críticos e atuantes sobre os desafios contemporâneos, seja este local, regional ou global, visto que o espaço escolar tem como função social de possibilitar que os alunos desenvolvam suas habilidades e competências fundamentais que garantirão sua autonomia e capacidade decisórias futuras (Busquets, 1998). Assim ao instigar a sensibilização e oportunizar no processo de ensino e aprendizagem o desenvolvimento do senso crítico e científico dos alunos para a preocupação com as temáticas que inferem sobre a vida humana em sociedade visa à melhoria da qualidade de vida para as gerações presentes e futuras.

Sendo assim, o presente texto está organizado em três seções: na primeira, na tratamos sobre as ponderações e considerações sobre as características entre a dicotomia da (a) criticidade e criticidade; na segunda, apresentamos uma discussão sobre a transição do senso comum ao pensamento crítico e na terceira seção, apresentamos a formação do pensamento crítico no processo de ensino e aprendizagem.

Nesse sentido esse estudo tem como objetivo apresentar fundamentos para a formação do senso crítico a partir do processo de ensino e aprendizagem a partir das dimensões socioculturais, ambientais, políticas e econômicas. Tendo em vista que as discussões possibilitam reflexões e adoção de posturas pessoais e comportamentos sociais construtivos, colaborando para a construção de uma sociedade mais justa com maior igualdade social em um ambiente saudável.

\section{Metodologia}

O objetivo desta pesquisa foi buscar fundamentos a partir da revisão de literatura sobre as orientações políticopedagógica, filosóficas e epistemológicas como instrumento de formação do senso critico a partir da apropriação do conhecimento científico partindo do pressuposto da preocupação incessante perante a complexa dinâmica das práticas educativas no contexto escolar no que tange o processo de ensino e aprendizagem onde se torna evidente o desgaste de um ensino pautado em modelos tradicionais, mecanicistas e conservadores no processo de ensino e aprendizagem. Assim a pesquisa tem sua,

Tomada num sentido amplo, pesquisa é toda atividade voltada para a solução de problemas; como atividade de busca, indagação, inquirição da realidade, é a atividade que vai nos permitir, no âmbito da ciência, elaborar um conhecimento, ou um conjunto de conhecimentos, que nos auxilie na compreensão desta realidade e nos oriente em nossas ações (Pádua, 1997, p. 29).

Para cumprimento do objetivo proposto foi adotada estratégia metodológica qualitativa, utilizando-se a técnica de levantamento e análise documental (Calado; Ferrera, 2015). A pesquisa qualitativa, segundo Higgs; Cherry (2009) refere-se a avaliações e interpretações críticas e qualitativas, ou seja, não matemáticas.

Para Ludke e André (2015), o procedimento do pesquisador na abordagem qualitativa é estar atento à multiplicidade de dimensões de uma determinada situação ou problema e após a análise dos dados, ele lança possibilidades de explicação da realidade, tentando encontrar princípios subjacentes ao fenômeno estudado e situar as suas descobertas num contexto mais amplo; trata-se de um esforço de construção ou estruturação de um quadro teórico, dentro do qual o fenômeno possa ser interpretado e compreendido. 


\section{Resultados e Discussão}

\subsection{A dicotomia entre as características da (a) criticidade e criticidade}

Todo ser humano precisa interagir com o meio em que está inserido, e atualmente, essa interação tem se tornado ainda mais importante uma vez que a sociedade tem passado por inúmeras transformações que exigem que os sujeitos não apenas se adaptem a esse processo de mudanças, mas assumam posicionamentos e se pronunciem de forma crítica frente os fatos que permeiam a nossa realidade.

Para que o indivíduo consiga desenvolver seus conhecimentos e aprimorar suas ideias, é necessário articular as reflexões sobre os conhecimentos que já possui aos novos, num processo permanente que favoreça a apreensão crítica da realidade.

Considerado em sua dimensão mais ampla, o pensamento crítico constitui um dos mecanismos por meio do qual é possível compreender melhor o mundo, posicionando-se diante dele, contribuindo significativamente para a revisão e construção de novos conhecimentos. O pensar criticamente envolve conhecimento sobre o próprio conhecimento, pois o pensador crítico deverá entender que há diversos tipos e estilos de pensamentos, reflexões, inferências e comunicação, dependendo do contexto onde estão inseridos.

A sociedade atual caracteriza-se por estar sendo constantemente pensada. Nós, como sujeitos ativos em nossas interações sociais, agimos, pensamos, questionando-nos; não damos por certa a realidade que nos rodeia, e sim sabemos da existência de outros contextos e outras práticas que põem "entre aspas" nossa normalidade. Constantemente, devemos filtrar a informação e envolvermo-nos na sociedade para sobreviver devido à pluralidade de formas de vida e maneiras de fazer. Devemos decidir à pluralidade entre opções possíveis, sabendo que aquilo de "para toda a vida" é algo que não acontece nem no trabalho e nem no casamento (Flecha; Tortajada, 2000, p. 26)

Para isso, a formação do sujeito crítico, autônomo, com desenvolvimento de sua subjetividade torna-se ainda mais evidente, pois todo ser crítico consegue racionalizar e compreender melhor tudo o que faz, vivencia e sente os fatos que fazem parte do seu cotidiano. Por isso, a reflexão crítica deve ser considerada como um movimento interno, como crescimento de cada indivíduo que necessita exercer seu papel no contexto em que vive.

Para Castanho (2000), o sujeito que não pensa criticamente se justifica pelas próprias crenças e as considera óbvias e naturais, ou seja, uma questão de filosofia pessoal. Na maioria das vezes defende as crenças em evidências irrelevantes e não consegue fundamentar idéias em evidências sólidas.

Acontece que, ao grande apelo por criticidade, respondeu-se às vezes como um não saber direito quais as possibilidades e quais os limites do senso crítico, bem como com certa ausência de autocrítica que predispunha à arrogância de se imaginar que se pode criticar tudo, todo o tempo, com ou sem o devido conhecimento daquilo que se fosse criticar (Castanho, 2006, p. 54).

Estudos revelam que grande parte dos sujeitos que não conseguem se posicionar de forma crítica por não dominarem os assuntos que os situa no mundo, não possuem conhecimentos que possam sustentar o desenvolvimento de uma argumentação, de uma reflexão ou até mesmo de um posicionamento crítico.

Assim, ser crítico significa ter condições de discernir, distinguir, interpretar, julgar fatos e assuntos mediante o uso de alguns critérios pré-estabelecidos. Fazendo uso de tais critérios tem-se a possibilidade de analisar determinada situação e, por meio da criticidade, demonstrar um posicionamento positivo ou negativo perante tal situação. Percebe-se, assim, que a criticidade servirá para mediar o posicionamento sobre determinado assunto, uma vez que através da criticidade podem ser apontadas as razões que instigaram a assumir essa ou aquela posição.

Seja como for, as avaliações críticas não podem estar permeadas de arrogância, ao contrário, devem apresentar uma determinada visão, uma leitura possível não meramente pautada na subjetividade. 
Não posso dizer que uma situação seja errada ou inaceitável porque não se afina com meus valores pessoais, pois isso vai ao ponto de colocar-me como referência do mundo. No entanto, não posso deixar de afirmar - isto sim - que, vivenciamos os valores que vivencio e cultivando os critérios que cultivo, tenho uma leitura pessoal negativa em relação à mencionada situação. (Regis Morais, 2000, p. 56).

A criticidade não é permeada por tensões nem conflitos, mas sim se fundamenta na serenidade das argumentações maduras, pois no momento em que o sujeito se posiciona de forma crítica sua individualidade deve ser respeitada e a individualidade das outras pessoas também, uma vez que o senso crítico precisa garantir a convivência harmoniosa entre os diferentes sujeitos.

Criticar significa avaliar situações, pronunciamentos, por meio de critérios bem definidos e bem explicitados, para que assim o exercício crítico não perca sua dimensão de relatividade.

[...] a criticidade é algo necessitado de abrangência, pois antes de tudo, precisaremos fazer a crítica do existir como um todo: em sua historicidade, em sua politicidade, em sua afetividade e em sua produção de bens intelectuais. Afinal não podemos nos demitir da única coisa que nos difere dos demais animais da escala zoológica: nossa condição de seres pensantes (Regis Morais, 2000, p. 57).

A criticidade não pode ser concebida como um processo de pensamento sem orientação, ao contrário, precisa ter um propósito muito bem definido diante dos problemas que devem ser analisados além de nossas próprias intenções e atuações pessoais.

Ser crítico, segundo Carraher (2011), envolve uma curiosidade intelectual que se baseia não somente em satisfazer e solucionar as problemáticas através de conversas sociais. A curiosidade intelectual depende de um investimento do indivíduo durante muito tempo a fim de compreender fenômenos profundamente.

A pessoa com senso crítico levanta dúvidas sobre aquilo em que acredita, explora rigorosamente alternativas por meio da reflexão e avaliação de evidências, com a curiosidade de quem nunca se contenta com o seu estado atual de conhecimento. Tende a ser produtora de conhecimento ao invés de consumidora de um conhecimento previamente pronto, assim, não aceita passivamente as ideias dos outros. Na maioria das vezes sua curiosidade é tão aguçada que acaba encontrando questões de interesse em fenômenos que os outros não julgam necessário explicar.

Além dessa atitude de curiosidade intelectual mencionada por Carraher (2011), o pensador crítico, segundo o autor, precisa ter uma tolerância e até predileção por estados cognitivos de conflito, em que o problema ainda não é totalmente compreendido. Dessa forma, o sujeito crítico,

[...] não pode ficar aflito quando não sabe 'a resposta correta, essa ansiedade pode impedir a exploração mais completa do problema. Segundo, ter curiosidade intelectual implica em ter honestidade intelectual, a qual não é simplesmente uma questão do caráter do individuo. O pensador menos exigente consigo mesmo tende a ver as interpretações que quiser ou que satisfaçam as exigências mínimas (o que o professor queria). Honestidade intelectual significa estar disposto a reformular posições diante de novas informações, a questionar nossas opiniões e a questionar posições que constituem modas intelectuais - a forma mais poderosa de dogmatismo. Terceiro, uma atitude de curiosidade intelectual implica em adotar perspectivas múltiplas, para examinar questões sob várias óticas. (Carraher, 2011, p. 21)

A consciência crítica de como as ideias são produzidas e construídas, caracteriza o senso crítico, como menciona Carraher (2011), como sendo não somente um conjunto de habilidades e atitudes cognitivas, mas sim um tipo de consciência social da comunicação, em que os fatos passam a ser realmente discutidos, questionados, analisados e até mesmo influenciados pela visão crítica do sujeito que o analisa. Quando existe a preocupação de verificar como as ideias foram construídas e 
produzidas, verifica-se que o sujeito age sobre aquilo que está sendo observado, questionado e não se mostra imparcial perante as questões que lhe são apresentadas.

O pensador crítico não é polivalente que entra em qualquer campo para elucidar suas questões fundamentais. Cada campo tem suas próprias premissas, o seu próprio "bom senso", suas próprias perspectivas. Assim, embora haja certas características gerais no desenvolvimento do senso crítico, o exercício do senso crítico num determinado campo exige conhecimento intimo das questões conceituais, das tradições, dos conflitos atuais, dos paradoxos e dos estilos comunicativos enfim um conhecimento das práticas e da rede de significados naquele campo. Por isso, o senso crítico exige, além de certos processos cognitivos e atitudes, uma experiência ampla no campo especifico de conhecimento em que se atua (Carraher, 2011, p. 21).

O indivíduo que não apresenta criticidade não cria e nem avalia as evidências apropriadas para desenvolver seu conhecimento, tende a aceitar tudo passivamente e somente defende pontos de vistas que já foram defendidos de antemão por outras pessoas.

Ao assumir uma postura crítica, o indivíduo assume também o papel de criador do conhecimento, efetiva suas buscas e passa a estudar as evidências que podem esclarecer determinadas dúvidas. Parte de uma posição humilde em relação ao seu conhecimento, e apresenta sua própria opinião e justifica suas expectativas no decorrer do processo reflexivo.

Carraher (2011) menciona que o pensador crítico exige a coerência que a lógica fornece, mas reconhece seus limites. Primeiramente, reconhece que muitas ideias desprovidas de uma lógica rigorosa têm valor e considera a adequação das ideias que aceita como premissas. O senso crítico exige o reconhecimento de que nossas ideias não são fatos, pois fatos não são considerados problemáticos, não são questionados, é aquilo que se afirma sem dúvida.

Não é surpreendente, então, notarmos a tendência entre indivíduos menos críticos a encarar ideias e opiniões como fatos. Talvez não haja nada que proteja nossas ideias e opiniões como fatos. Talvez não haja nada que proteja nossas ideias da reflexão mais que a crença de que elas sejam "naturais", evidentes e reais. Ao apresentarmos nossas ideias como fatos, nós as colocamos acima de qualquer discussão. Justamente por isso precisamos refletir sobre a natureza dos fatos e a sua distinção de outros tipos de ideias (Carraher, 2011, p. 119).

A necessidade de questionamento de ideias é uma característica do pensador crítico, que geralmente encontra dificuldades em saber quais são as opiniões mais válidas num debate sobre algum assunto. Percebe-se que o indivíduo que realiza uma leitura crítica nota as posições diferentes apresentadas perante qualquer problemática e criticamente as avalia e verifica qual é a mais apropriada.

Sem dúvida, o pensador crítico não é livre de valores e nem pretende ser, pois pode ter convicções e assumir compromissos fortes. Valoriza a coerência, a clareza de pensamento, a reflexão e a observação cuidadosa porque deseja compreender melhor a realidade social.

O indivíduo crítico contribui de forma significativa para a construção de novos conhecimentos e, consequentemente, para o desenvolvimento das ciências. Para isso, no entanto, precisa de clareza e rigor no seu pensamento, da coragem para adotar uma perspectiva ampla dos problemas que estuda, precisa estabelecer associações, usar sua intuição, formular novas ideias, ver semelhanças entre eventos e áreas do conhecimento aparentemente não relacionado, explorar implicações, sugerir novas investigações, olhar os fenômenos de novas maneiras.

\subsection{Transição do senso comum ao pensamento crítico}

Sabe-se que na realidade a capacidade crítica do sujeito não se desenvolve de maneira tão rápida, até mesmo por que toda e qualquer pessoa apresenta uma concepção de mundo própria, com elementos sociais que partilham de um mesmo modo de pensar e de agir. Na verdade somos conformistas, aceitamos os fatos e fazemos parte de uma realidade de "homens- 
massas", que segundo Gramsci (1981), não possui uma concepção de mundo crítica e coerente, mas sim uma concepção do senso-comum, transmitida de geração em geração que muitas vezes se transforma em crença religiosa, em doutrinas que não são esquecidas.

Quando a concepção do mundo não é crítica e coerente, mas ocasional e desagregada, pertencemos simultaneamente a uma multiplicidade de homens-massa, nossa própria personalidade é composta de uma maneira bizarra: nela se encontram elementos dos homens das cavernas e princípios da ciência mais moderna e progressista; preconceitos de todas as fases históricas passadas, grosseiramente localistas, e instituições de uma futura filosofia que será própria do gênero humano mundialmente unificado (Gramsci, 1981, p. 12).

Segundo Gramsci (1981), o conhecimento adquirido por tradição, herdado dos antepassados e ao qual são acrescentados os resultados da experiência vivida na coletividade, é chamado de senso comum e pode ser classificado como um conjunto de ideias que permite ao sujeito interpretar a realidade de maneira não reflexiva, uma vez que confunde com crenças e valores. É um conhecimento ingênuo, melhor dizendo, não crítico, fragmentário e conservador, pois resiste a mudanças.

O senso comum costuma ser subjetivo, exprime sentimentos e opiniões individuais ou de grupos, variando de uma pessoa para outra ou de um grupo para outro, dependendo das condições em que vivemos. Por isso, torna-se heterogêneo e individualizador, em que cada coisa ou cada fato nos aparece como um indivíduo ou como um ser autônomo. Na maioria das vezes, o senso comum limita-se a resolver problemas de ordem prática. Portanto, se o conhecimento funcionar dando a resposta desejada a determinada situação, o mesmo conhecimento continuará sendo utilizado sem muitos questionamentos.

O conhecimento comum, ou senso comum limita-se na descrição das aparências dos fenômenos, não examinando suas causas e efeitos profundos. Isso não quer dizer, no entanto, que o conhecimento comum não possa resolver certos problemas com sucesso, mas, em muitos casos a sua aplicabilidade, marcada por crenças, pode causar efeitos desastrosos.

Para Gramsci (1981), o senso comum geralmente reúne numa só opinião ou numa só idéia coisas e fatos julgados semelhantes e tende a estabelecer relações de causa e efeito entre eles. Não se surpreende e nem se admira com a regularidade, constância, repetição e diferença das coisas, mas, ao contrário, a admiração e o espanto se dirigem para o que é imaginado como único e extraordinário. Essa insuficiência do senso comum é consequência do apego a consequências imediatas e ao fato dele permanecer ao nível das aparências, em vez de procurar explicações mais profundas em função de fenômenos não diretamente observáveis.

No senso comum, segundo Badaró (2005, p. 22), “encontra-se um pensar, um saber que é usado e reproduzido de forma mecânica, sem que se tenha essa consciência. Trata-se de concepções que muitas vezes são impostas pelo meio externo ou pela tradição." Nesse sentido, o senso comum pode ser definido como um conjunto de opiniões e crenças admitidas numa determinada sociedade, associada à vida cotidiana, onde prevalece uma consciência ingênua de pessoa, de mundo e de ciência.

Percebe-se que a atitude do senso comum, diferentemente da atitude crítica, como afirma Badaró (2005), é costumeira, visto que não desconfia da veracidade das certezas, da adesão imediata das coisas e gera uma ausência de crítica e falta de curiosidade.

O saber comum observa um fato de modo genérico (imediato), sem dele fazer as devidas depurações (é isto que aprendemos muitas vezes na escola). A ciência, ao contrário, o analisa, retirando de suas indagações, a sua objetividade e a sua verificabilidade, através de uma linguagem rigorosa, cujos conceitos são definidos de modo a evitar ambiguidades (Badaró, 2005, p. 29).

Torna-se de certa forma evidente o porquê de certa resistência natural dos indivíduos em abandonar a visão do senso comum e assumir uma nova postura com perspectiva crítica, reflexiva e científica da realidade, considerando que, ao pensar 
criticamente, a segurança e a certeza sobre determinado fato ou assunto deixa de prevalecer. Abre-se espaço para novas formas de pensar, não mais pautadas na subjetividade e na opinião própria, mas em opiniões que se constroem na cientificidade do conhecimento historicamente construído. No entanto, a forma de pensar comum do indivíduo não deve ser menosprezada, mas deve ser superada. Segundo Gramsci (1981), o bom senso é o núcleo sadio do senso comum. Qualquer pessoa quando estimulada no exercício de compreensão crítica torna-se capaz de estabelecer juízos sábios que contribuem para a formação de novas reflexões.

Muitas vezes, quando ocorre a passagem do senso comum para o bom senso, o indivíduo é excluído da tomada de decisões da própria comunidade onde está inserido. Em sociedades não democráticas, por exemplo, as informações não circulam igualmente em todas as camadas sociais, por isso nem todos têm direito iguais de consumir e produzir cultura.

Acredita-se que qualquer indivíduo que possua determinada liberdade será capaz de desenvolver a autoconsciência, de elaborar criticamente o seu próprio pensamento e de analisar criticamente a situação em que vive.

Criticar a própria concepção do mundo, portanto, significa torná-la utilitária e coerente e elevá-la até o ponto atingido pelo pensamento mundial mais desenvolvido. Significa, portanto, criticar, também, toda a filosofia até hoje existente, na medida em que ela deixou estratificações consolidadas naquilo que somos realmente, isto é, um "conhece-te a ti mesmo", como produto do processo histórico até hoje desenvolvido, que deixou em ti uma infinidade de traços recebidos sem beneficio no inventário (Gramsci, 1981, p. 12).

Criar uma nova cultura, deixando a visão do senso comum para adotar uma concepção de mundo criticamente coerente, não significa fazer individualmente descobertas, mas sim, difundir verdades criticamente já descobertas e socializálas. Como afirma Gramsci (1981, p. 13) "transformá-las em base de ações vitais, em elemento que conduza o homem a pensar coerentemente e de maneira unitária a realidade presente."

O conhecimento crítico permite ao indivíduo, como menciona Badaró (2005, p. 34), "um processo de apropriação mental com relação ao mundo no qual faz parte, na tentativa de elaborar explicações e reflexões distintas dos diferentes fatos e fenômenos que o circundam." O conceito de criticidade está desta forma, associado ao ato de voltar-se para si mesmo na busca de reflexões que levem o indivíduo a compreender melhor o que faz, vivencia e sente.

Segundo Badaró (2005), a formação do senso crítico está vinculada a uma alteração qualitativa da maneira de pensar e compreender o mundo. Esta alteração provoca uma reinterpretação e o enriquecimento do conhecimento já existente.

A proposta deste novo conhecimento demonstra que o mundo é cognoscível pelo homem. O mundo verdadeiro da teoria, por oposição ao mundo aparente do conhecimento comum e do realismo ingênuo, modifica a maneira de aprendermos a realidade. $\mathrm{O}$ sujeito cognoscente deve analisar de modo crítico a realidade, uma análise de conceitos científicos, a fim de evidenciar o crescimento dialético por aproximações com o objeto. A realidade é, portanto irreduzível ao sujeito, a possibilidade de aproximações entre sujeito e o objeto são inesgotáveis (Badaró, 2005,p. 35).

A opinião que está situada na mente, como um obstáculo, precisa ser desconstruída para que seja dado lugar para a construção do conhecimento, que vai exigir do indivíduo uma postura crítica, objetiva e sistemática, que o levará a desvincular-se da visão de senso comum de realidade e das opiniões intuitivas.

Para que haja essa superação do senso comum, a educação precisa exercer seu papel de forma significativa contribuindo para uma aprendizagem que desenvolva nos educandos o desenvolvimento do senso crítico. A educação precisa favorecer uma formação baseada na aquisição e aprimoramento de conhecimentos e permitir o desenvolvimento de habilidades necessárias para a sociedade atual, tais como seleção e processamento de informações, autonomia, capacidade para tomar decisões, trabalho em grupo, flexibilidade, senso crítico, que são imprescindíveis nos diferentes contextos sociais. 


\subsection{A formação do senso crítico no processo educativo}

Vários estudos revelam que a educação, em especial a escolar sistematizada, tem e assume papel primordial na formação dos alunos como sujeitos atuantes da realidade social em que se inserem. As instituições escolares vêm sendo instigadas a repensar o seu papel frente às transformações que se revelam na sociedade atual. Nesse sentido, entende-se que é necessário superar a educação que se caracteriza e se baseia na mera transmissão de valores e conhecimentos e propiciar uma educação participativa e interativa, que objetive a formação integral do aluno.

Essas atitudes devem estar ligadas a outras como compreender conceitos e teorias cientificas, adquirir competências cognitivas, associadas à prática de ciência, bem como fomentar uma atitude cientifica de olhar o mundo e, por fim, desenvolver competências para usar o conhecimento científico na resolução de problemas (Badaró, 2005, p. 108).

Pode-se acrescentar que a escola deve se preocupar com a formação cultural e científica de todos os seus alunos e assim oferecer a eles contato cultural, científico, técnico, estético, ético, evidenciando a preocupação e o desenvolvimento do pensamento crítico.

Nesse processo são fundamentais determinadas habilidades, dentre as quais podem ser destacadas: o desenvolvimento da criatividade, da sensibilidade, da imaginação; a preparação para o processo produtivo, tecnológico e comunicacional, bem como a formação da cidadania crítica, que oferece condições para que todo indivíduo consiga interferir criticamente na realidade para transformá-la e não apenas formar para integrar o mercado de trabalho.

A educação, por sua vez, só favorecerá o pensamento crítico quando desempenhar um papel significante nos processos sociopolíticos, pois está relacionada ao desenvolvimento da autoconsciência crítica. Essa crítica implicaria o rompimento com o discurso antigo, seja no âmbito teórico ou prático, para recriar um novo processo cultural. A perspectiva baseada na criticidade deve ser capaz de neutralizar a teoria antiga, mostrando sua incoerência.

Verifica-se, no entanto, que para que esta antiga teoria seja neutralizada e a visão do senso comum superada, a escola e seus atores devem assumir o papel central do processo de ensino aprendizagem em prol da construção de uma visão de mundo unitária, que liberte os homens do senso comum e de sua filosofia espontânea.

A elaboração de uma visão organizada de mundo não se faz arbitrariamente em torno de uma ideologia qualquer, vontade de alguma personalidade, de grupos fanáticos, filosóficos ou religiosos. A não adesão ou adesão da massa a uma ideologia demonstra a crítica da racionalidade histórica dos modos de pensar. As construções arbitrárias são as primeiras a serem eliminadas na competição histórica; já as construções que correspondem as exigências de um período histórico complexo e orgânico terminam sempre por se impor e prevalecer, ainda que atravessem muitas fases intermediarias nas quais a sua afirmação ocorre apenas em combinação mais ou menos bizarras e heteróclitas (Gramsci, 1999, p. 111).

A escola, em seu sentido mais amplo, colabora de forma significativa para reforçar uma consciência autônoma, educar os alunos para pensarem de modo claro, libertando-os de uma simples visão caótica, colaborando segundo Gramsci (1999), para uma educação que não se limite à simples enunciação teórica de princípios e métodos, mas que realize a articulação do trabalho educativo com a indução, a dedução, a lógica formal e a dialética.

Assim, a educação passaria a assumir realmente um caráter emancipatório, contribuindo para a formação do indivíduo que age e reflete sobre sua própria história.

Com essa visão de escola, como menciona Gramsci (1999), a velha escola seria abolida e substituída por uma escola que, mediante o que ensina, luta contra todas as sedimentações tradicionais de concepções de mundo, a fim de difundir uma concepção mais moderna, que visa ao desenvolvimento pleno e coletivo do indivíduo, fazendo com que ele consiga participar ativamente da realidade a qual está inserido, com vistas a transformá-la e socializá-la. 
Gramsci (1999), afirma que a criticidade pode e deve ser construída diariamente, em um processo lento e de formação continuada, em que o sujeito entrará para um mundo magnífico, de valores de relevância estética e tecnológica e com esses valores conseguirá identificar novas técnicas e construções que lhe permitirão assumir pontos de vista diversos perante todo e qualquer fato ou assunto que possam ser colocados em pauta.

A formação do senso crítico depende de certo amadurecimento intelectual, da formalização do pensamento e de uma educação crítica que esteja ligada aos diferentes e possíveis papéis que a educação poderia e pode desempenhar dentro de um contexto sócio-político particular.

No entanto, estudos revelam que para favorecer a construção desse pensamento crítico não basta ao professor dominar a arte de ensinar, é preciso dominá-la e colocá-la em prática fazendo uso do conhecimento que possui, para que o conteúdo a ser ensinado possa estar repleto de significado para o aluno.

[...] o senso crítico depende de certo amadurecimento intelectual e formalização do pensamento não encontrados em criança, mesmo as mais inteligentes. O senso crítico refere-se a habilidades já desenvolvidas (e não apenas potenciais), presumivelmente através de leitura, reflexão e da própria prática (Carraher, 2011, p. 20).

Portanto, o processo de ensino-aprendizagem deve propiciar o desenvolvimento de habilidades que levem o indivíduo a uma formação crítica e reflexiva e o professor ofereça subsídios para que o aluno eleve o seu nível de informações que são fundamentais para a problematização e apreensão da realidade.

O professor não pode assumir uma prática desprovida de reflexão, nem tão pouco se mostrar imparcial diante do conhecimento historicamente construído, pois está atitude retratará seu descomprometimento com a formação social, cultural e intelectual do seu aluno.

Nota-se que o professor precisa ter o compromisso da investigação e da análise critica verificadora de certas teorias e práticas. Precisa favorecer o enriquecimento do repertório intelectual de seu aluno e este só será construído por meio da prática de leituras diferenciadas e relacionadas ao conteúdo trabalhado em sala ou aos fatos e acontecimentos diários. O professor a todo o momento deve instigar o seu aluno a ler, pesquisar, vivenciar situações para que esse universo cognitivo possa ser ampliado diariamente. É a partir dessas experiências cognitivas que o aluno conseguirá expor ideias com expressividade, argumentar para defendê-las ou negá-las, usando sua criatividade, dando um enfoque diferente do já conhecido.

Nesse sentido, "a autoridade intelectual" citada por Carraher (2011) necessita ser deixada de lado e a convivência humana se constituirá por meio da luta de inteligências, ou seja, o confronto entre as diversas formas de ler e entender a realidade. A educação na sociedade da informação deve basear-se na utilização de habilidades comunicativas, de tal modo que,

permita-nos participar mais ativamente e de forma mais crítica e reflexiva na sociedade. Se pretendermos superar a desigualdade que gera o reconhecimento de determinadas habilidades e a exclusão daquelas pessoas que não tem acesso ao processamento da informação, devemos pensar sobre que tipo de habilidades está sendo potencializado nos contextos formativo e se com isso é facilitada à interpretação da realidade a partir de uma perspectiva transformadora (Flecha; Tortajada, 2000, p. 31).

A educação necessita romper com o discurso tradicional que se baseia nas teorias conservadoras, que defendem uma educação baseada na reprodução, e aderir a um processo integrador, participativo e permanente, embasado na ação conjunta de todos os envolvidos no processo, sem nenhum tipo de exclusão, oferecendo respostas às necessidades dos alunos.

A formação de um sujeito crítico precisa deixar de ser privilégio de uma parcela de nossa sociedade, tornando-se necessário que um número maior de pessoas desfrute desta riqueza infinita de assuntos e áreas de informações. A realidade educativa precisa contemplar a experiência humana, possibilitar a todo o momento um aprendizado significativo que leve em 
consideração as características específicas de cada aluno, compensando as diferenças, não prejudicando a individualidade nem tão pouco a formação do senso critico.

A educação precisa mudar a sua cultura, superando a cultura do individualismo, que se encontra tão presente dentro das instituições educativas, por uma cultura baseada no trabalho compartilhado, a partir do desenvolvimento de atividades abertas que contribuam para a formação de cidadãos democráticos e, acima de tudo críticos.

Enfim, não basta mudar as pessoas para transformar a educação e suas consequências. Temos sim, que mudar as pessoas e os contextos (as pessoas em seus contextos) educativos e sociais. Dessa forma, começaremos a mudar muitas coisas, entre elas valorizar e fazer com que se valorize a humanidade realmente como ela é: um aglomerado de diferenças culturais, de etnias, de religiões, de conhecimentos, de capacidades, de ritmos de aprendizagem, etc., que é precisamente uma das características que nos define como seres humanos (Imbernón, 2000, p. 86).

Para que esses propósitos possam ser alcançados e as mudanças ocorram gradativamente é necessário que a instituição gere uma atitude de autocontrole, propiciando a troca de ideias, de experiências e de propostas. Os princípios de convivência baseados na liberdade, na troca de experiências, no diálogo, na reflexão e na responsabilidade, estimulando a dignidade humana baseada na solidariedade e respeito mútuo, na consciência social e política, devem ser recuperados dentro da instituição.

Lamentavelmente, o que se verifica nos espaços escolares é que os conteúdos ainda vêm sendo transmitidos de forma fragmentada, desarticulada, neutros, desprovidos de significado e os processos de construção e de reconstrução estão longe de fazer parte deste processo educativo.

A incoerência apresentada entre teoria e prática é muito grande, uma vez que ocorre a supervalorização de atividades que se preocupam apenas com a repetição e memorização e não com a compreensão e entendimento.

Esse processo educativo, como afirma Gebran (2002), contribui para a paralisia da atitude crítica do aluno e reforça cada vez mais a incapacidade de estabelecimento de relações entre conhecimentos adquiridos, sem evidenciar as condições socioeconômicas, culturais e históricas da realidade social. O ensino torna-se alienador, pois não permite a participação efetiva do aluno neste processo educativo e no processo de construção do conhecimento, nem tão pouco questiona, problematiza ou critica o saber que a ele é transmitido. Dessa forma, perde-se o que seria o principal objetivo da educação, o favorecimento de um processo criativo e inovador para o aluno, onde a construção, organização e transmissão de conhecimentos estariam intrinsecamente ligados à transformação e desenvolvimento do senso crítico.

O conhecimento, enquanto meramente informativo transformou-se na própria mercadoria e a ciência tornou-se algo que é ativamente desenvolvido pelo próprio capital para sua incorporação como força produtiva. Aquilo que é definido como sendo conhecimento escolar passa a se constituir numa seleção particular e arbitraria de um universo muito mais amplo de possibilidades e o grande educador passa a ser o capital (Gebran, 2002, p. 59).

Garrido (2001) aponta para o papel do professor para articular a construção e formação do pensamento crítico no processo de ensino e aprendizagem,

O papel mediador do professor pode contribuir significativamente para essa aprendizagem. Exige-se dele habilidades para: criar um clima de busca e de respeito mútuo; estimular a expressão do aluno e seguir de perto o seu raciocínio ajudando-o a verbalizá-lo; incitar a classe a examinar e esclarecer o ponto de vista ou as dúvidas do companheiro; colocar questões instigadoras, desestabilizadoras e significativas que estimulem o reexame das ideias e promovam a relevância do diálogo; avaliar o debate, retomando os caminhos percorridos, proporcionando ao grupo uma visão de síntese e um sentimento de realização intelectual (Garrido, 2001, p. 131). 
Portanto, os educadores, sujeitos-atores deste processo, devem preparar o aluno para apreensão e análise consciente da realidade, numa prática de reflexão permanente e contínua. Assim, torna-se fundamental a análise e a reflexão das práticas educativas vigentes que envolvem um processo de reorganização da ação pedagógica presente nos ambientes escolares.

Daí a importância de recuperar uma pedagogia da pergunta e não só da resposta, favorecedora de uma aprendizagem baseada mais no dialogo do que no monologo. Falamos de imaginação, de capacidade, de estimulo, etc. algo que aprendemos com a nova escola do séc. XXI (Imbernon, 2000, p. 89).

O papel da educação seria então o de rever toda a sua estrutura, os seus agentes, formas de administração e, principalmente, facilitar e favorecer a participação de todos aqueles que, direta ou indiretamente, estão envolvidos nesse processo. Torna-se necessário rever o papel da instituição escolar e seu papel na educação dos cidadãos e, para isso, é preciso fazer uso da imaginação na busca de alternativas.

Torna-se evidente que a escola necessita rever com urgência a sua prática educativa com vistas à adoção de proposições educativas que considerem as noções de liberdade, igualdade, dignidade humana, democracia, moral, de responsabilidade social passando assim a valorizar a importância da formação do indivíduo conhecedor dos seus direitos, crítico, ativo e transformador da realidade.

As instituições escolares precisam urgentemente aderir às novas transformações sociais e preparar os alunos a enfrentarem os conflitos que fazem parte do cotidiano. Para esse enfrentamento, no entanto, eles precisam estar munidos de habilidades que são importantes, como consciência crítica, debate, trabalho conjunto e flexibilidade, que permitirão a construção de um pensamento capaz de selecionar informações relevantes, argumentar e questionar, tomar decisões, etc.

\section{Considerações Finais}

A elaboração deste estudo envolvendo sobre a formação e desenvolvimento do senso crítico se consolida com o envolvimento na relação homem, sociedade e natureza aproximando os estudantes e professores da sua própria realidade, contribuindo de forma significativa para a formação e o desenvolvimento do senso crítico e sua criticidade em relação aos problemas relacionados que inferem sobre a existência humana na Terra.

Assim, na pesquisa procuramos conceituar o sujeito crítico, retratando a relevância na apropriação do conhecimento científico para favorecer a formação do sujeito crítico, apontando ainda para a necessidade de práticas educativas que favoreçam cada vez mais esta formação, e tornem sujeitos atuantes sobre as questões sociais, políticas, econômicas, ambientais, culturais entre outras. Entendemos que a criticidade se fundamenta em argumentações convincentes, na avaliação precisa de fatos, acontecimentos, assuntos, enfim o sujeito crítico se pronuncia e faz uso do pensar, explora e refleti. Toda consciência crítica pauta-se na curiosidade, na procura, na análise crítica e na verificação sobre aquilo que esta sendo observado.

É notável que esta formação crítica não tem sido propiciada muitas vezes nos ambientes escolares, pois a formação presente hoje nos âmbitos de nossa sociedade é conformista, homogênea, tradicional e favorecedora da passividade. Verifica-se que as instituições de ensino necessitam urgentemente rever as atuais práticas educativas e preparar nossos alunos para a vida, para enfrentarem a realidade social, educacional, política, cultural presente.

Assim, ressalta-se que deve existir a preocupação em estabelecer, no contexto educativo, a compreensão do respeito à sociedade com enfoque na perspectiva de transformação social e na formação de alunos críticos, humanizados e emancipados e com isso fomentar para um novo modelo no processo de ensino e aprendizagem e uma nova postura, que busque a construção crítica e científica dos saberes produzidos, que se preocupe com a socialização dos mesmos de maneira igualitária e que os 
alunos possam ser orientados na construção do conhecimento que será propiciado por meio de trocas diárias entre os sujeitos envolvidos no processo.

Nesse sentido, o professor assume papel imprescindível no processo de construção do conhecimento e formação do senso crítico, pois é ele o responsável, o facilitador e o mediador, que oferecerá aos alunos condições para o seu crescimento humano, intelectual, reflexivo, crítico, autônomo. Ao atuar como mediador do processo educativo deixa aflorar suas experiências, indaga-se a respeito do conhecimento a ser transmitido, seu valor e sua importância, ensina os alunos que a educação é um processo humano, participativo, permeado por descobertas, contribui para a formação do sujeito, sua transformação e para a humanização dos alunos numa perspectiva de inserção social crítica e transformadora.

Nesse sentido, esse processo se tornará possível quando os ambientes educacionais organizarem seu espaço de modo a transformar a sala de aula em um espaço em que os alunos possam experimentar situações que os levem a busca, a comparação, a crítica do pensamento e das ações.

Além disto, se faz necessário e fundamental, que seja feita uma reflexão sobre o processo de ensino e nas escolhas pessoais e coletivas bem como nas nossas responsabilidades perante as atuais e futuras gerações, visto que existem muitas incertezas e inseguranças causando relutância e divisões. Assim, estas discussões em torno da formação do senso crítico como instrumento de ensino deve ultrapassar as paredes burocráticas e chegar rapidamente, às salas de aula, e isto não pode acontecer apenas por obra de um professor ou de um grupo, ou escola ou rede, estas discussões têm que sair da Política de Estado e alcançar todo o sistema de ensino.

É necessário que a escola não seja mais vista como um simples espaço de transmissão de conceitos, mas sim como um lugar de apropriação do conhecimento científico para que o processo de ensino-aprendizagem tenha sentido e seja instrumento eficaz para se compreender a interação entre o homem, sociedade e a natureza. É o caminho para que cada indivíduo assuma suas responsabilidades em busca de uma melhor qualidade de vida para si e para os outros.

É inegável que nos dias atuais se faz necessário uma reestruturação no processo de ensino e aprendizagem bem como na formação continuada dos professores para que haja mudanças nas estratégias metodológicas que favoreçam a formação crítica, participativa, autônoma, criativa, dos alunos. Pois na sua maioria, as aulas não promovem situações para o pensar sobre valores e critérios de decisão frente ao mundo, frente as relações humanas, aos fatos que permeiam a realidade. $\mathrm{O}$ conhecimento muitas vezes torna-se algo estático, descontextualizado e o professor deixa de assumir seu papel frente à formação crítica do aluno, que acaba por se tornar um mero expectador do processo de ensino aprendizagem.

Nesse sentido, a educação escolar para contribuir significativamente para a formação do cidadão crítico e participativo precisa por ela própria por em prática situações que promovam o desenvolvimento da autonomia de pensamento, iniciativa, participação nas decisões. Desta forma os professores precisam repensar sua prática e se preocuparem com a emancipação intelectual de seus alunos.

Com procedimentos, estratégias e atitudes diversificadas, essa cultura da criticidade pode vir a fazer parte do processo educativo de forma mais abrangente. Para isso, os educadores, em coletividade, devem viabilizar o desenvolvimento do senso crítico a partir de temáticas que tragam as dimensões culturais, sociais, políticas, ambientais entre outras para a centro dos debates nas escolas com aulas reflexivas e dialogadas, leituras e discussões de textos de forma reflexiva e crítica, debates coordenados, pesquisas orientadas, projeções de vídeos e filmes com roteiros para reflexão e debates, práticas de campo, sempre articulando com a realidade em que o aluno está inserido e com a realidade na qual irá atuar.

\section{Referências}

Badaró, C. E. (2005). Epistemologia e Ciência: reflexão e prática na sala de aula. Edusc. 
Brasil (2004). Ministério da Educação. Secretaria de Educação Média e Tecnológica. Orientações curriculares do ensino médio: ciências da natureza, matemática e suas tecnologias. MEC/SEB.

Brasil (1998a). Ministério da Educação e do Desporto. Secretaria de Educação Fundamental. Referencial curricular nacional para a educação infantil: conhecimento de mundo. MEC/SEF, v. 03.

Brasil (1998b). Ministério da Educação. Secretaria de Educação Fundamental. Parâmetros curriculares nacionais: Ciências Naturais, MEC / SEF, 1998b.

Brasil (1999). Lei n ${ }^{\circ}$ 9.795, de 27 de abril de 1999. Dispõe sobre a Educação Ambiental, institui a Política da Educação Ambiental e dá outras providências. Diário Oficial da União,

Busquets M. D. et al., (2000). Temas transversais em educação: bases para uma formação integral. Ática.

Cachapuz, A. F., Praia, J. F., Jorge, M. P. (2002). Ciências, Educação em ciências e ensino de ciências. Ministério de Educação.

Calado, S. S \& Ferreira, S. C. R. (2005). Análise de Documentos: método de Recolha e Análise de Dados. Metodologia de Investigação I. Departamento de Educação da Faculdade de Ciências da Universidade de Lisboa.

Carvalho, I. (2004a). Educação ambiental crítica: nomes e endereçamentos da educação. In: MMA/ Secretaria Executiva/ Diretoria de Educação Ambiental (Org.). Identidades da educação ambiental brasileira. Brasília: MMA.

Carvalho, A. M. P. (2004b). Ensino de Ciências: unindo a pesquisa e a prática. Pioneira Thomson learning.

Carvalho, I. C. M. (2006) Educação ambiental: a formação do sujeito ecológico. (2a ed.), Cortez.

Carraher, D. W. (2011). Senso crítico: do dia-a-dia às ciências humanas. (9a ed.), Pioneira.

Castanho, M. E. (2006). A criatividade na sala de aula universitária. In: Veiga, I. P. A. Castanho, M. E. L. M. (Orgs.) Pedagogiauniversitária: a aula em foco. Campinas: Papirus, p. 75-90.

Candau, V. M. (2000). Reinventar aescola. Petrópolis: Vozes.

Chassot, A. (2006). Alfabetização científica: questões e desafios para a educação. (4a ed.), Ed. Unijui.

Declaração de Budapeste. (1999). Marco general de acción de la declaración de Budapest.

Flecha, R. \& Tortajada, I. (2000). Desafios e saídas educativas na entrada do século. In: Imbernón, F. (Org.) Educação no século XXI: os desafios do futuro imediato. (2a ed.), Artmed, p. 21-36.

Fourez, G. (1987). Enseignement de Sciences et Société. Extrait de Vallonte, n. 8.

Fracalanza, H., Amaral, I. A., Gouveia, M. S. F. (1986). O ensino de ciências no primeirograu. Atual.

Freire, P. (1998). Pedagogia da Autonomia. Paz e Terra.

Garrido, E. (2001). Por uma nova cultura escolar: o papel mediador do professor entre a cultura do aluno e o conhecimento elaborado. In: Severino, A. J.; Fazenda, I. C. A. (Orgs.) Conhecimento, pesquisa e educação. Campinas: Papirus, p. 125-142.

Gebran, R. A. (2002). Espaço e cidadania: a construção social do conhecimento geográfico. In: Ferri, L. M. G. C. Educação, sociedade e cidadania. Londrina: [s.n.].

Gramsci, A. (1981). Concepção dialética da história. (4a ed.), Civilização Brasileira.

Gramsci, A. (1999). Introdução ao estudo da filosofia. A filosofia de Benedetto Croce. Civilização Brasileira.

Guimarães, L. R. (2009). Atividades para Aulas de Ciências. Nova Espiral.

Guimarães, M. (2000). Educação ambiental: No consenso um embate? (4a ed.), Papirus.

Higgs, J. \& Cherry, N. (2009). Doing qualitative research on practice. In: Higgs, J; Horsfall, D; Grace, S. (Eds.). Writing Qualitative Research on Practice. Rotterdam (NE): Sense Publishers, p. 3-12.

Imbernón, F. (2000). Amplitude e profundidade do olhar: a educação ontem, hoje e amanhã. In: Imbernón, F. (Org.) Educação no século XXI: os desafios do futuro imediato. (2a ed.), Artmed, p. 77-94.

Jacobi, P. R. (2005). Educação Ambiental: o desafio da construção de um pensamento crítico, complexo e reflexivo. Educação e Pesquisa, 31, 233-250, 2005.

Jacobi, P. R. (2000). Meio ambiente e redes sociais: dimensões intersetoriais e complexidade na articulação das práticas coletivas. Revista de Administração Pública. Rio de Janeiro: Fundação Getúlio Vargas, 34, 131-158.

Krasilchik, M. \& Marandino, M. (2004). Ensino de ciênciase cidadania. Moderna.

Leff, H. (2003). A complexidade ambiental. Traduzido por Eliete Wolff. Cortez.

Loureiro, C. F. B. Trajetória e fundamentos da educação ambiental. (2a ed.), Cortez, 2006a.

Loureiro, C. F. B. (2006b). Complexidade e Dialética: Contribuições à praxis política e emancipatória em Educação Ambiental. Educ. Soc., 27, 131-152. 
Research, Society and Development, v. 10, n. 7, e31010716655, 2021

(CC BY 4.0) | ISSN 2525-3409 | DOI: http://dx.doi.org/10.33448/rsd-v10i7.16655

Ludke, M. \& André, M. (2015). Pesquisa em educação: abordagens qualitativas. E.P.U.

Maia, N. F. (1997). A ciência por dentro. (4a ed.), Vozes.

Medeiros, R. \& Mercês, M. (2001). Educação Ambiental: história e prática. Apostila NADC, UFRJ.

Pádua, E. M. M. (1997). Metodologia de pesquisa: abordagem teórica-prática. (2a ed.), Papirus.

Regis Morais, J. F. (2004). A criatividade como fundamento humano. In: Veiga, I. P. A.; Castanho, M. E. L. M. (Orgs.) Pedagogia universitária: a aula em foco. (4a ed.), Papirus, p. 51-74.

Souza, N. M. (2000). Educação Ambiental, dilemas da prática contemporânea. Universidade Estácio de Sá/Thex. 